\title{
Managing Rational and Not-Fully-Rational Knowledge
}

\author{
Jozef Hvorecký, Jozef Šimúth, Branislav Lichardus
}

Vysoká škola manažmentu, Panónska cesta 17, 85104 Bratislava, Slovakia jhvorecky@vsm.sk, jsimuth@vsm.sk, blichardus@vsm.sk

\begin{abstract}
Knowledge management $(K M)$ is a range of strategies and practices in organizations to identify, create, represent, distribute, and enable the adoption of insights and experiences. Knowledge is present in organizations in two forms: explicit (wellstructured and unambiguously captured) and tacit (vague or informal, based on experience and beliefs stored in human brains). These two types split knowledge management into its "hard" and "soft" components. Each of them can contribute to an organization's development and prosperity but must be controlled in different ways. In hard knowledge management, the elements of knowledge, insight and experience are embedded in organizational processes and practice. To control them, traditional (rational) managerial approaches can be applied. However, people do not always act rationally. To benefit from knowledge embodied in individuals, more sophisticated strategies should be used. First we show examples of lower rationality studied by earlier researchers. Then, we use the SECI model to disclose situations deserving managers' special care. We demonstrate the presence of non-rationality in all SECI stages and exemplify its manifestations. Our conclusions can help managers concentrate on the core problems of knowledge management and apply it more efficiently.
\end{abstract}

Keywords: Knowledge management; Rationality; Irrationality; Emotions; SECI Model; Tacit \& explicit Knowledge, Managing tacit knowledge

\section{Irrationality in Management}

Since the Enlightenment, rational thinking and reasoning has been considered the indisputably best method of decision-making. In textbooks [e.g. 1, p. 631], rational methods are presented first. Usually they are divided into five stages:

- Recognition and definition of a problem or opportunity;

- Search for alternative courses of action;

- Gathering and analysis of data about alternatives;

- Evaluation of alternatives;

- Selection and implementation of a preferred alternative. 
Formal approaches are effectively used as bases for designing and implementing of knowledge systems and expert systems [2], for constructing optimization algorithms, for designing robot's movements and for planning exactly specified processes.

On the other hand, recent research indicates that the level of rationality in human's decision-making declines with the growing level of managerial position. Isenberg [3] noted that in making their day-to-day and minute-by-minute tactical maneuvers, senior executives tend to rely on several general thought processes such as intuition; managing a network of interrelated problems; dealing with ambiguity, inconsistency, novelty and surprise; and integrating action into the process of thinking. Agor [4] came to a similar conclusion when he found that without exceptions, top managers in every organization differ significantly from middle and lower mangers in their ability to use intuition to make decisions on the job. He adds that women and people with Asian background demonstrate this trait more than other groups.

Glass [5] observed that intuitive approaches are neglected: "Given our choice of decision-making techniques, most of us would use quantitative approaches first and rational ones second; intuition would come at or near the bottom of the list". He shows that not-fully-rational decisions must be made even in fields in which rationality seems to be dominant, such as programming and software development and stresses: We invent other names for it, cloaking its apparent irrationality in socially acceptable terms. For example, we speak of "gut" decision makingdecisions coming from some deeply felt belief that goes against the grain of the environment surrounding the decisions.

There exist examples of using not-fully-rational approaches in managerial activities regardless of their branch of industry or administration. Brunson [6] shows that choices are facilitated by narrow and clear organizational ideologies, and actions are facilitated by irrational decision-making procedures which maximize motivation and commitment. Guo [7] understands the problems caused by not-fully-rational procedures in strategic marketing but stresses their positive contribution, too:

1) Irrational factors guide the strategy of the manager in gathering and compiling information.

2) Irrational factors support strategy on the part of the manager when carrying out information analysis.

3) Irrational factors help improve the efficiency and quality of decision making.

4) Irrational factors promote the smooth implementation of strategic decision.

Dann and Pratt [8] believe that the non-conscious information processing system evolved early in humans and is based on automatic and relatively effortless processing of information. According to them, researchers view intuition as one of the products of this non-conscious, or automatic, system of information 
processing. They underline that the term "intuition" is used in different ways: either addressing the process running in human brain or its outcome or both. They propose an exhaustive list of its interpretations. It leads them to introducing the terms intuiting for the process and intuitive judgments for its outcomes.

In describing the intuiting, they identify its following features:

- It is subconscious,

- It involves making holistic associations,

- It is fast,

- It results in affectively charged judgments.

Their research neighbors to our field of interest - knowledge management - as they also take into account the domain knowledge factors, in particular the heuristic or expert ways of derivation of new knowledge from the existing one.

All of the authors underline the positive contribution of the not-fully rational approach in their research fields regardless whether they call them "emotions", "intuition" or "irrationality". In their research, the concepts do not mean "no wisdom" or "nonsense". They rather specify a kind of reasonableness not fully controlled by our erudition and formal reasoning.

In this paper, we study the role of such interpreted irrationality in knowledge management, its manifestations and implications to managers' activities.

\section{Knowledge in Managers' Perception}

Defining something as subtle and intangible as knowledge is almost impossible. The likely best way is posting a series of alternative definitions, each of them applicable under different conditions. The Oxford English Dictionary's definition [10] specifies knowledge as:

- Expertise and skills acquired by a person through experience or education;

- What is known in a particular field or in total;

- Theoretical or practical understanding of a subject;

- Awareness or familiarity gained by experience of a fact or situation;

- Facts and information.

The first description is appropriate when describing the capabilities of educated persons; the second is more appropriate for defining a (scientific) discipline; the third one speaks about the "depth" of our knowledge. The fourth indicates that knowledge can grow, while the fifth says that it can also be expressed in fixed terms. 
Knowledge helps people solve their problems. Different problems require distinct pieces of knowledge, as Table 1 shows. Almost all elements of knowledge mentioned above are illustrated in the table: expertise (in surgery), familiarity with the situation (setting up the diagnosis), understanding of the field (taxation), facts and information (tax ranges), theoretical and/or practical understanding of the subject (cleaning the oven).

Table 1

Examples of knowledge necessary for solving problems

\begin{tabular}{|l|l|l|}
\hline \multicolumn{1}{|c|}{ Problem } & \multicolumn{1}{c|}{ Knowledge } & \multicolumn{1}{c|}{ Solution } \\
\hline Calculating salaries & $\begin{array}{l}\text { Person's income, } \\
\text { Tax regulations, } \\
\text { Calculations }\end{array}$ & $\begin{array}{l}\text { Net Income, } \\
\text { Tax }\end{array}$ \\
\hline Appendicitis & $\begin{array}{l}\text { Setting up the diagnosis, } \\
\text { Surgery experience, } \\
\text { After-operation treatment }\end{array}$ & Healthy patient \\
\hline Dirty oven & $\begin{array}{l}\text { Household skills, } \\
\text { Detergent application }\end{array}$ & Clean oven \\
\hline Talking to dead & Spiritual practices & Evoked ghosts \\
\hline
\end{tabular}

Source: Hvorecky \& Kelemen [11]

As one can also see, the validity of the solution does not depend merely on the individuals' gained information, experience, and skills, but also on their beliefs. Only people who believe in ghosts are ready to consider "spiritual practices" as a category of knowledge; others will likely complain. The opponents will also reject the both proposed methods and solutions because (according to their conviction) spirits cannot be evoked.

The reason for the dichotomy is rooted in different quality of our knowledge. Some of its pieces are undisputable (e.g. $1+2=3$ ) as they have been verified to the maximum human potential. All professions have their quantum of unconditional knowledge - the basis of the discipline. Some pieces of knowledge are accepted as correct by mutual agreement. For example, according to the ISO standard, the boiling point of water is $100^{\circ} \mathrm{C}$, while the imperial system posts it at $212^{\circ} \mathrm{F}$. Finally, some elements are based on individual faith only, such as the above-mentioned existence of ghosts. They can be characterized as our believed knowledge.

Using their personalized pieces of knowledge, different people tend to process the same situation differently and to act in different ways. Managers should be aware of these differences as undisclosed substantial divergence among them may harm any team's cooperation. For example, the Mars Climate Orbiter space experiment crashed due to discrepancies in computations of its orbit, caused by mixing up the metric and imperial measuring systems [12]. 
The necessity of managing the variety of pieces of knowledge dispersed in humans led to the birth of knowledge management - a discipline studying the optimal approaches to its exploitation in organizations.

\section{Knowledge Management}

Knowledge Management (KM) is a range of strategies and practices organizations use to identify, create, represent, distribute, and enable the adoption of insights and experiences [13]. In accordance to this discipline, knowledge is present in two forms [14]: explicit (well-structured and unambiguously captured) and tacit (vague, informal, and based on experience and beliefs).

Explicit knowledge can be stored on paper, media or by other appropriate means. Computer programs represent the most advanced forms of explicit knowledge today. Knowledge is transformed into the abstract machines capable of getting data from their environment, remembering and processing them and producing results. The most advanced forms mimic human reasoning. Transferring our explicit knowledge into production lines, machines and robots is one of the principal trends of contemporary science and technology. Mathematical and chemical formulas, optimization and validation methods, recipes and operational instructions - all are examples of explicit knowledge. Their sources and bearers can be quite easily identified. This allows us to implement this part of knowledge management more easily.

Tacit knowledge is stored in human brains only. One can register its presence only when it is applied. An example is the interpretation of statistical data. Different individuals are likely to read the same data in different ways depending on their experience, familiarity with the controlled environment, emotions, political views, etc. Even if some guidelines on interpreting statistical data can be proposed, there is no universal method, and the result depends substantially on its interpreter. Occasionally, the person might not even be aware of possessing a piece of tacit knowledge. Then, his/her activity may seem random and its outcome simply good luck.

Tacit knowledge represents a considerable portion of our knowledge. In accordance to Abidi et al [15], it may contribute to two thirds of the decisions of logistics workers. Other authors [16] estimate its prevalence as being as great as 90:10. Due to the hidden character of tacit knowledge, similar ratios represent estimations based on their particular author's conviction.

Two types of knowledge divide knowledge management into its "hard" and "soft" sections. In hard knowledge management, the well-specified, exact and captured elements of knowledge, insights, and experiences are embedded in organizational processes and practice. Traditional (highly rational) managerial approaches can be 
applied for their control. One of the aims of hard knowledge management is to transfer selected elements of tacit knowledge into explicit ones using of knowledge engineering [2].

Below, we concentrate on the management of tacit knowledge. We show that it is still possible to apply some traditional methods to it. For example one can map "who knows what" - naturally with the limitations rooted in lower chances to verify its existence and depth and in the impossibility to catch it all.

\section{The SECI Model}

Our research has a methodological character. Its main aim is to build a supporting tool for the "who knows what" mapping. As the "who" part is indivisibly tied to the particular organization and its goals, we concentrate on "what" components and develop a list of capacities to be searched for. Such a list might serve as a guideline during the mapping.

The SECI model [17] is a subject-independent model describing the relationship between explicit and tacit knowledge. Its original purpose is to demonstrate the way of knowledge development inside organizations.

\begin{tabular}{c|c|c|}
\multirow{2}{*}{ TACIT KNOWLEDGE } & \multicolumn{1}{c}{ TACIT KNOWLEDGE } & \multicolumn{1}{c}{ EXPLICIT KNOWLEDGE } \\
\cline { 2 - 3 } EXPLICIT KNOWLEDGE & Socialization & Externalization \\
\cline { 2 - 3 } & Internalization & Combination \\
\cline { 2 - 3 } & &
\end{tabular}

Figure 1

The SECI Model

Bearers of tacit knowledge interact with bearers of (possibly different) tacit knowledge during Socialization. It is performed by interpersonal communication and/or intrapersonal insights. This is the most traditional form of learning and is present in any human community.

To achieve a person-independent knowledge, people try to express their internal understanding of objects and methods in a commonly accepted way using various forms of Externalization. That results in discussion of a subject in a standardized, comprehensible format. These presentations (numbers, texts, graphs, formulas, etc.) create a basis for the wider distribution of knowledge as the "dialogue" between the author and consumer of the piece of knowledge does not depend on their geographic location and time distance.

The pieces of knowledge expressed in their formal notation can be processed by their receivers. Such Combination may lead to new pieces of knowledge. Computers and robots are also capable of executing combination when it is incorporated in their controlling programs. On the other hand, a machine- 
performed combination represents just a part of all actions in this area because people perform intellectual activities which belong to this category and cannot be executed by computers yet.

In the last stage, people try to interpret the outcomes of their activity and want to comprehend them. Through Internalization, the new piece of knowledge becomes an integral part of our individual knowledge ready for its future application.

The knowledge-acquiring processes runs:

- Inside each of the four quadrants: During Socialization, we learn by communicating thoughts and experiences with our partners. We absorb their style of thinking, study their mentality and effects of emotions on them etc. During Externalization we learn to visualize our ideas and demonstrate them in a legible manner. We study which approaches are successful and which are not; we remember them in order to excel later. During Combination we learn to control our moves to get fair results and search for more efficient combination methods. During Internalization we adjust the new piece of knowledge into our already existing knowledge system and start comprehending its role in it.

- The clockwise order indicated by the initial letters S-E-C-I shows that learning runs in cycles. The ideas are born in our minds $(\mathrm{S})$. Then we try to express them in a more concise way $(\mathrm{E})$. This preliminary outcome is then elaborated in order to test its validity, acceptability and usefulness (C). Finally, we "shape" the new piece to a contour changing it into a part of our internal knowledge weaponry (I).

- Eternally: Every new piece of knowledge is presented to the community and discussed. Its "socialization" begins and may lead to new ideas. As a result, the knowledge processing acquires the form S-E-C-I-S-E-C-I-S-...

Thus, the SECI model shows a life-cycle of knowledge with its multiple reincarnations. Due to its eternal elaboration, our knowledge turns out to be deeper, wider and abundant with the time. The model also demonstrates the evolutionary character of our knowledge which constantly switches between explicit and tacit ones.

\section{Tacit Knowledge as a Regular Part of Knowledge- related Processes}

The conviction of some authors about the prevalence of tacit knowledge over the explicit variety is likely based on the fact that tacit knowledge must be applied even during Combination, which is seemingly a pure "explicit - explicit" activity. 
For example, all mathematical calculations are not just formal manipulations with its symbols. One must know which formulas are applicable, which of them will be the most likely lead to the result, how to order them, whether the result is meaningful, and so on. Table 2 shows some of the not-fully rational activities accompanying the particular SECI processes.

Table 2

Not-fully-rational activities behind the SECI model

\begin{tabular}{|c|c|}
\hline Socialization & Externalization \\
\hline Story-telling & Speaking and writing excellence \\
\hline Discussion & Capturing of the idea's core \\
\hline Opposing common opinions & Formalization \\
\hline Listening to other opinions & Introduction of a new notation \\
\hline Showing example behaviour & Posing "right" questions \\
\hline Teaching and training & Demonstrating skills \\
\hline \multicolumn{2}{|l|}{ Brain storming } \\
\hline Internalization & Combination \\
\hline Digesting of a new piece of knowledge & Lateral thinking \\
\hline Practicing a new activity & Creating analogies \\
\hline Implementing a problem solving method & Selection of the right knowledge processing \\
\hline Learning a new formal notation & method \\
\hline Becoming involved in the topic & Identification of the new piece of \\
\hline $\begin{array}{l}\text { Understanding potential "usefulness" of } \\
\text { knowledge }\end{array}$ & ledge \\
\hline
\end{tabular}

Notice that our list is not exhaustive. It rather contains typical examples derived from the authors' experience. Depending on the type of the organization and the character of its functions, some of the activities are more important than others. To manage tacit knowledge, therefore, means completing the above list in accordance with the aims of the organization, to select principal "irrational" activities and to set up their priorities in human resource development and its control.

\section{Introducing the Management of Tacit Knowledge}

Realize that the tacit knowledge management processes include a large portion of rationality. In other words, managing irrationality can be a rather rational process. Still, compared to the management of explicit knowledge, managers must apply different approaches. Their methods must be less direct and more based on cooperation with their employees. A typical strategy can be specified using the medical sequence "prevention-diagnosis-treatment". 


\subsection{Prevention}

The prevention starts with selecting appropriate employees to knowledge worker positions. They must be not only educated and skilled, but also interested in their profession and motivated to cooperate on the goals of the organization. Their job duties must offer them enough room for grasping and digesting additional knowledge and experience and for discussing their validity and value. Contemporary human resource management is aware of some of factors shown in Table 2 and pays attention to them. But it does not focus on all variables. For example, how do recruiters assess an applicant's courage to oppose common opinions? When they disclose it, will they accept it as a positive feature of the applicant or not? How will they decide whether the applicant would use this skill appropriately at work?

Some tacit knowledge elements can be verified quite easily, despite their notfully-rational character. For example, speaking and writing skills can be tested with a relatively high precision. However, some others are not as easy to measure, e.g. the ability to capture the core of ideas. Some skills can only be judged by relevant specialists, e.g. quality of design. Again, due to the irrational character of the notion of quality, their judgment can still be misleading and can occasionally be neglected. In such cases, the reason for the refusal should be a rational one. Some elements of tacit knowledge may not be tested simply because even their owner is unaware that he or she possesses them, e.g. the ability to act as an example.

Creating a proper and comfortable working environment is another presumption. It should support the exchange of informal thoughts and an atmosphere of relevant criticism without fear of consequences. The team as a whole should cover the list of expected explicit and tacit knowledge and skills. Every team member should be familiar with the other team members' capability to execute them as well as with their priorities in their execution.

In order to form an efficient and effective team, the triple character of knowledge has to be considered:

- All unconditional knowledge must be present. If its pieces are absent, the team efforts must be concentrated on acquiring them, otherwise the task cannot be finished.

- Prior to the commencement of work, there must be an exhaustive mutual agreement on all task-related elements of accepted knowledge. Inconsistencies among them might lead to fatal consequences.

- Finally, the individuals' believed knowledge must be harmonized. If, for example, some team members question the ethical aspects of their work, their frustration could negatively influence their involvement up to the level of its sabotage. 


\subsection{Diagnosis}

As a result of the untouchable character of knowledge, the significance of the knowledge worker's knowledge, skills and experience cannot be fully assessed during the prevention process. It can be only completed when its first results are presented in practice. Their evaluation should take into account their "useful irrationality", i.e. on the assessment of the knowledge workers' creativity and its application in their duties. Thoroughly designed and constantly monitored diagnostic methods must become a tool of every knowledge worker's manager. They must be based on a regular observation and evaluation of the work progress. They must be job-oriented and flexible enough to reflect the creative and innovative characteristics of the tasks.

The manager must control whether the particular team member is capable of accomplishing his/her duty and/or to fix what was done wrong. As the manager can hardly be a specialist in all specific fields, the situation can result in an absolute dependence of the manager on his/her subordinate(s). Managers without good discussion skills and patience to listen to the knowledge workers' opinions will be in a tough situation.

\subsection{Treatment}

Managing tacit knowledge requires permanent collaboration and mutual support. Flattening is a typical strategy of contemporary organizations. Their authoritarian hierarchies are changing. Instead of giving and receiving orders, control in organizations is mostly based on trust. In organizations having a rigid and/or conservative culture, building "islands of positive deviation" is a possible strategy. Such cells should demonstrate model behavior. The top management should value and reward them in order to demonstrate its devotion to their principles.

In general, the proper strategies are based on facilitating the knowledge workers' motivation rather than on giving orders to them. Success also depends on the quality of diagnostic methods because early-discovered problems can be fixed with less pain. The treatment methods must accent collaboration, freedom to act and feelings of responsibility for the outcome in each team and all of its members.

\section{Conclusions}

In their function, organizations apply many concepts and procedures which are not rational in the traditional sense. Knowledge management must accept this fact as a basis for its approaches. During our analysis, we have identified several not-fullyrational elements. All of them relate to tacit knowledge. The SECI model helped us to identify abilities and skills that support individual processes that participate in creating new knowledge. There is not (and can hardly ever be) a comprehensive list here; many others will be found in the future. As irrationality is a natural part 
of human nature, its position must be better specified; otherwise, knowledge management will not reach its potential. Consequently this would not bring its prospective benefits.

In our future research we will try to disclose them and, hence, to identify more specific methods of their diagnosis and treatment. We therefore understand our described research as a pilot study. Based on its results we have formulated our recommendations that could be instrumental to managers in focusing on the core problems of tacit knowledge management. In agreement with the authors named in our first chapters, we believe that even not-fully-rational aptitude of our brains can be developed by appropriate learning and training methods. Their combination with effective tacit knowledge management can help the organizations to promote and prosper.

\section{References}

[1] David A. Buchanan, Andrzej A. Huczynski: Organizational Behavior. Prentice-Hall, Pearson Education, Harlow UK, 2010

[2] Jozef Kelemen et al: Knowledge in Context. Iura Edition, Bratislava, 2010

[3] Daniel J. Isenberg: How Senior Managers Think. Harvard Business Review, November-December 1984

[4] Weston H. Agor: How Top Executive Use Their Intuition to Make Important Decisions. Business Horizons, January-February 1996

[5] Robert L. Glass: Intuition Role's in Decision Making. IEEE Software, January/February 2008, pp. 95-96

[6] Nils Brunsson: The Irrationality of Action and Action of Rationality: Decisions, Ideologies and Organizational Actions. Journal of Management Studies, Vol. 19, Issue 1 (Jan. 1982) pp. 29-44

[7] Yongbo Guo: Study on Irrational Strategic Management. International Journal of Marketing Studies, Vol. 1, No. 2 (2009) pp. 92-95

[8] Erik Dane, Michael G. Pratt: Exploring Intuition and Its Role in Managerial Decision Making. Academy of Management Review, 2007, Vol. 32, No. 1, pp. 33-54

[10] Simpson, J., Weiner, E. (eds.): Oxford English Dictionary. Oxford University Press, 1989

[11] Jozef Hvorecký, Jozef Kelemen (eds.): Readings in Knowledge Management. Iura Edition, Bratislava 2011

[12] Wikipedia: Mars Climate Orbiter. http://en.wikipedia.org/wiki/Mars_Climate_Orbiter (Accessed on 8 June 2012)

[13] Wikipedia: Knowledge Management 
http://en.wikipedia.org/wiki/Knowledge_management (Accessed on 8 June 2012)

[14] Paul M. Hildreth, Chris Kimble: The Duality of Knowledge. Information Research, Vol. 8, No. 1, October 2002

[15] Hella Abidi, Matthias Krump, Thomas Keuschen: Industry Qualifications Framework Ligistics: Explicit and Tacit Knowledge and Qualifications in Logistics Industry. In: Thorsten Blacker, Carlos Jahn, Wolfgang Kersten (eds.): Maritime Logistics in Global Economy, Josef Eul Verlag, Köln, 2011, pp. 327-345

[16] Beliz Ozorhon, Irem Dikmen, M. Talat Birgonul: Organizational memory formation and its use in construction. Building Research \& Information, Volume 33, Issue 1, 2005, pp. 67-79

[17] Nonaka, I., Takeuchi, H.: The Knowledge-Creating Company - How Japanese Companies Create the Dynamics of Innovation. Oxford University Press, London, 1995 